\title{
Endovascular treatment of acute ischemic stroke due to anterior circulation large vessel occlusion beyond 6 hours: a real- world study in China
}

Qing Huang ${ }^{1 \dagger}$, Mengmeng $\mathrm{Gu}^{1 \dagger}$, Junshan Zhou ${ }^{1}$, Teng Jiang ${ }^{1}$, Hongchao Shi ${ }^{1}$, Xiangliang Chen ${ }^{1 *+}$ and Yingdong Zhang ${ }^{1,2^{*+}}$

\begin{abstract}
Background: We aimed to assess the safety and efficacy of endovascular treatment (EVT) in patients with anterior circulation emergent large vessel occlusion (ELVO) beyond $6 \mathrm{~h}$ from symptom onset in a real-world cohort of patients in China.

Methods: We retrospectively examined 305 patients with anterior circulation ELVO treated with EVT. Patients were divided into two groups: treated with known onset within $6 \mathrm{~h}(n=238)$ and beyond $6 \mathrm{~h}(n=67)$. Multivariable logistic regression and ordinal shift analyses were used to evaluate the associations between onset-to-groin puncture time and safety and efficacy outcomes.

Results: Treatment beyond $6 \mathrm{~h}$ was not associated with symptomatic intracranial hemorrhage within $48 \mathrm{~h}(\mathrm{~s} \mid \mathrm{CH}$; odds ratio [OR] 2.03, 95\% confidence interval [Cl] 0.48-8.57, $p=0.334$ ), in-hospital mortality (OR 1.95, 95\% Cl 0.48$7.91, p=0.348$ ), successful recanalization (modified Thrombolysis in Cerebral Infarction score 2b or 3; OR 0.73, 95\% $\mathrm{Cl} 0.31-1.73, p=0.470$ ), favorable functional outcome (modified Rankin Scale score 0-2; OR 0.55, 95\% Cl 0.25-1.23, $p=0.145$ ), and functional improvement (modified Rankin Scale shift by 1-point decrease; common OR 0.80, $95 \% \mathrm{Cl}$ $0.45-1.42, p=0.450$ ) at 3 months compared with treatment within $6 \mathrm{~h}$. Futher interaction analysis showed that stroke etiology did not modify the associations between onset-to-groin puncture time and outcomes $(p>0.05)$.
\end{abstract}

Conclusions: In this real-world study, after careful assessment, EVT beyond $6 \mathrm{~h}$ from known stroke onset was safe, effective and had comparable short-term outcomes to EVT within $6 \mathrm{~h}$.

Keywords: Endovascular treatment, Time window, Recanalization, Symptomatic intracranial hemorrhage, Functional outcome

\footnotetext{
* Correspondence: chenxl@njmu.edu.cn; zhangyingdong@aliyun.com

${ }^{\dagger}$ Qing Huang, Mengmeng Gu, Xiangliang Chen and Yingdong Zhang contributed equally to this work.

${ }^{1}$ Department of Neurology, Nanjing First Hospital, Nanjing Medical University, No.68, Changle Road, Nanjing, Jiangsu Province, People's Republic of China Full list of author information is available at the end of the article
}

(c) The Author(s). 2021 Open Access This article is licensed under a Creative Commons Attribution 4.0 International License, which permits use, sharing, adaptation, distribution and reproduction in any medium or format, as long as you give appropriate credit to the original author(s) and the source, provide a link to the Creative Commons licence, and indicate if changes were made. The images or other third party material in this article are included in the article's Creative Commons licence, unless indicated otherwise in a credit line to the material. If material is not included in the article's Creative Commons licence and your intended use is not permitted by statutory regulation or exceeds the permitted use, you will need to obtain permission directly from the copyright holder. To view a copy of this licence, visit http://creativecommons.org/licenses/by/4.0/. The Creative Commons Public Domain Dedication waiver (http://creativecommons.org/publicdomain/zero/1.0/) applies to the data made available in this article, unless otherwise stated in a credit line to the data. 


\section{Background}

The safety and effectiveness of endovascular treatment (EVT) for acute ischemic stroke (AIS) from anterior circulation emergent large vessel occlusion (ELVO) within $6 \mathrm{~h}$ after the onset of symptoms have been fully confirmed by recent large randomized controlled trials [1-5]. The subsequent meta-analysis showed that treatment delay would diminish the beneficial effects of EVT, and the benefit was no longer significant after $7.3 \mathrm{~h} \mathrm{[6].}$

More recent trials have shown that patients with AIS beyond $6 \mathrm{~h}$ of onset can still benefit from EVT under neuroimaging guidance [7, 8]. The DEFUSE-3 trial [8] (Endovascular Therapy Following Imaging Evaluation for Ischemic Stroke-3) and DAWN trial [7] (DiffusionWeighted Imaging or Computerized Tomography Perfusion Assessment With Clinical Mismatch in the Triage of Wake Up and Late Presenting Strokes Undergoing Neurointervention With Trevo) extended the time window of EVT to $16-24 \mathrm{~h}$ in carefully selected patients. However, the subjects of the two trials were patients with unwitnessed or wake-up stroke, that is, the onset time is actually unknown, and the actual onset time in some cases may still be within $6 \mathrm{~h}$. The real-world experience in western countries demonstrated that EVT beyond $6 \mathrm{~h}$ of known symptom onset was feasible and safe and did not increase the risk of symptomatic intracranial hemorrhage $(\mathrm{sICH})[9,10]$. Since the main etiology of ischemic stroke in Asian and Western populations are different, in that the Asian population mainly manifested with a higher proportion of large artery atherosclerosis (LAA) stroke [11-13], it is necessary to conduct a real-world study on patients with EVT beyond $6 \mathrm{~h}$ in the Asia population.

In this study, we assessed the safety and efficacy of EVT in AIS patients with acute anterior circulation ELVO beyond $6 \mathrm{~h}$ after symptom onset in a real-world cohort of patients in China.

\section{Methods}

\section{Patients}

Based on the Nanjing First Hospital Stroke (NFHS) Registry Program [14], we performed a retrospective review of consecutively recruited stroke patients with anterior circulation ELVO (occlusion of the internal carotid artery, and/or middle cerebral artery M1 or M2) treated with EVT between January 2016 and February 2020.

In accordance with the national guidelines, eligible patients were treated with intravenous thrombolysis within $4.5 \mathrm{~h}$ after the onset of symptoms. After exclusion of contraindications, patients admitted within $6 \mathrm{~h}$ of stroke onset were treated with EVT if they fulfilled the following criteria: 1) 18 years or older; 2) anterior circulation ELVO confirmed by CT angiography (CTA) or MR angiography (MRA); 3) no intracranial hemorrhage or subarachnoid hemorrhage on initial non-contrast CT; and 4) written informed consent. Before 2018, for patients admitted more than $6 \mathrm{~h}$ after stroke onset, the further neuroimaging criterion to treat with EVT was an infarction involving less than 1/3 MCA territory with a perfusion-diffusion mismatch ratio $\geq 1.2$. And since 2018 , the criterion was based on a target mismatch profile defined by the DEFUSE-3 trial (i.e. an ischemic core volume of $<70 \mathrm{~mL}$, a perfusion-diffusion mismatch ratio $\geq 1.8$ and a mismatch volume $\geq 15 \mathrm{~mL}$ ).

According to the purpose of this study, we further excluded patients if they fulfilled the following criteria: 1) with unknown onset of stroke (including unwitnessed and wake-up stroke); 2) had a pre-stroke modified Rankin scale (mRS) score $\geq 2$; and 3) had serious heart, liver or kidney dysfunction. Due to the retrospective nature of this study, written informed consent was waived by the ethics committee for the anonymized analysis of data collected as part of routine clinical care in this cohort.

\section{Clinical characteristics}

Data on demographics, stroke risk factors, laboratory indexes, stroke severity, neuroimaging, intravenous thrombolysis, onset-to-groin puncture time, and treatment profiles of EVT were extracted from the NFHS registry database. The etiology of ischemic stroke was classified by the Trial of Org 10,172 in Acute Stroke Treatment (TOAST) criteria [15]. The National Institutes of Health Stroke Scale (NIHSS) score was used to assess stroke severity at admission. Infarct volume after acute anterior circulation ischemic stroke was evaluated by two experienced neurologists ( $\mathrm{HS}$ and $\mathrm{XC}$ ) using the Alberta Stroke Programme Early CT Score (ASPECTS) $[16,17]$. Discrepancies were resolved by consensus. According to the time from known symptom onset to groin puncture, patients were divided into two groups: within $6 \mathrm{~h}$ and beyond $6 \mathrm{~h}$.

\section{Outcomes}

Safety outcomes included in-hospital mortality and $\mathrm{sICH}$ confirmed by neuroimaging (CT or MRI) within $48 \mathrm{~h}$. According to the Heidelberg Bleeding Classification, sICH was defined as the newly observed intracranial hemorrhage associated with any of the following conditions: 1) an increase of $\geq 4$ points in total NIHSS; 2) an increase of $\geq 2$ points in one NIHSS category; or 3 ) deterioration that led to intubation, hemicraniectomy, external ventricular drain placement, or any other major medical/surgical interventions [18].

The recanalization status was classified using the modified Thrombolysis in Cerebral Infarction (mTICI) score [19]. Successful recanalization was defined as 
mTICI score $2 b$ or 3 and was considered as an efficacy outcome [20].

Short-term functional outcomes were quantified using the mRS score at 90 days, which was evaluated as a routine part of the NFHS registry program through telephone interviews or face-to-face visits. Favorable functional outcome was defined as mRS score $0-2$ at 90 days. Functional improvement was defined as mRS shift by 1 -point decrease in $\mathrm{mRS}$ score at 90 days.

\section{Statistical analysis}

Normally and non-normally distributed continuous variables were reported as mean \pm standard deviation (SD) and median [interquartile range (IQR)], and were compared using Student's $t$-tests and Wilcoxon rank sum test, respectively. Categorical variables were presented as number (proportion) and compared using the Pearson's $X^{2}$ tests.

Multivariable logistic regressions were used to evaluate the associations between onset-to-groin puncture time ( $\leq 6 \mathrm{~h}$ and $>6 \mathrm{~h}$ ) and safety outcomes, efficacy outcome and functional outcomes. Multivariable ordinal logistic regression (ordinal shift analysis) was used to investigate the association between onset-to-groin puncture time $(\leq 6 \mathrm{~h}$ and $>6 \mathrm{~h}$ ) and functional improvement (a shift in the distribution of mRS scores) at 90 days. We also investigated whether the etiology of stroke modified the associations between onset-to-groin puncture time and outcomes by adding a multiplicative interaction term in the model.

All regression analyses were conducted with adjustments for the baseline variables reported to have significant effects on safety, efficacy, and functional outcomes, including age, sex, hypertension, diabetes mellitus, atrial fibrillation (AF), smoking, baseline NIHSS, baseline ASPECT score, TOAST classification, occlusion site, fasting blood glucose (FBG), total cholesterol (TC), triglyceride (TG), low-density lipoprotein (LDL) and intravenous thrombolysis.

All statistical analyses were performed using SPSS 23.0 software and a two-sided $p<0.05$ was considered statistically significant.

\section{Results}

A total of 384 consecutive stroke patients with anterior circulation ELVO (occlusion of the internal carotid artery, and middle cerebral artery M1 or M2) were treated with EVT between January 2016 and February 2020. Among them, 79 patients were further excluded, and eventually, 305 patients were included in the analysis (enrollment information shown in Fig. 1). Of the 305 enrolled patients, the mean age was $71.1 \pm 12.0$ years. The median baseline NIHSS score was 16 points (IQR 1119 ) and the median ASPECT score was 8 points (IQR 6-9). The median time from stroke onset to groin puncture was 243 (IQR 176-346) min. Successful

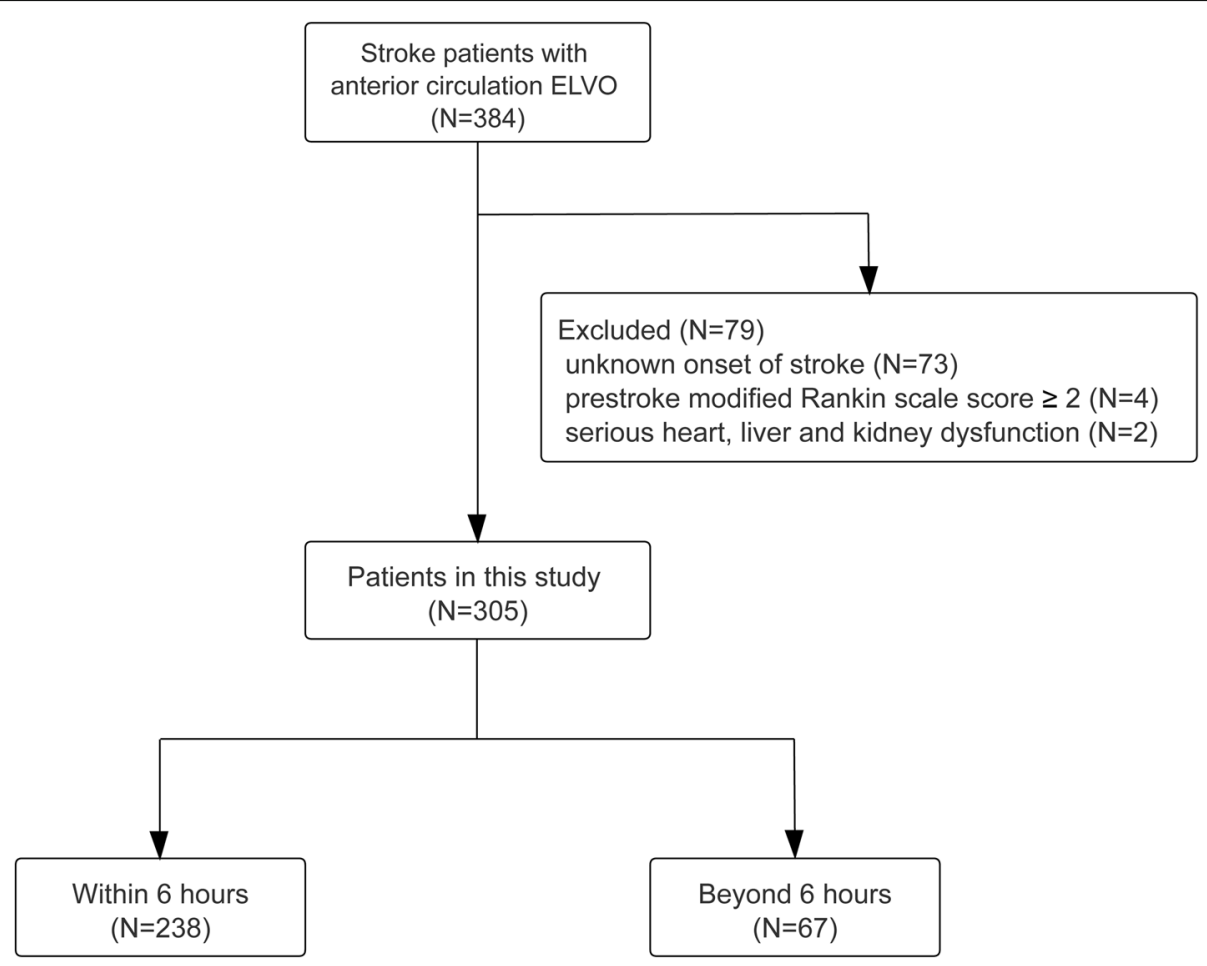

Fig. 1 Flow chart for study participants. Abbreviations: ELVO=emergent large vessel occlusion 
Table 1 Baseline characteristics of EVT patients treated within and beyond $6 \mathrm{~h}$ of onset

\begin{tabular}{|c|c|c|c|}
\hline & $\begin{array}{l}\text { Within } 6 \mathrm{~h} \\
(n=238)\end{array}$ & $\begin{array}{l}\text { Beyond } 6 \mathrm{~h} \\
(n=67)\end{array}$ & $p$ \\
\hline Age, mean $\pm S D, y$ & $72.3 \pm 1.6$ & $66.9 \pm 12.4$ & 0.001 \\
\hline Male, n (\%) & $135(56.7)$ & $39(58.2)$ & 0.828 \\
\hline Hypertension, n (\%) & $171(71.8)$ & $46(68.7)$ & 0.610 \\
\hline Diabetes mellitus, $\mathrm{n}(\%)$ & $53(22.3)$ & $16(23.9)$ & 0.781 \\
\hline Atrial fibrillation, n (\%) & $131(55.0)$ & $21(31.3)$ & 0.001 \\
\hline Previous stroke/TIA, n (\%) & $53(22.3)$ & $14(20.9)$ & 0.810 \\
\hline Smoking, n (\%) & $77(32.6)$ & $26(38.8)$ & 0.324 \\
\hline Baseline NIHSS, median (IQR) & $16(12-20)$ & $13(9-17)$ & 0.002 \\
\hline Baseline ASPECT score, median (IQR) & $8(6-9)$ & $7(6-9)$ & 0.497 \\
\hline TOAST classification, n (\%) & & & 0.006 \\
\hline Large artery atherosclerosis & $81(34.0)$ & $37(55.2)$ & \\
\hline Cardioembolism & $134(56.3)$ & $24(35.8)$ & \\
\hline Others & $23(9.7)$ & $6(9.0)$ & \\
\hline Occlusion site, n (\%), & & & 0.746 \\
\hline Internal carotid artery & $84(35.3)$ & $25(37.3)$ & \\
\hline Middle cerebral artery M1 & $133(55.9)$ & $38(56.7)$ & \\
\hline Middle cerebral artery M2 & $21(8.8)$ & $4(6.0)$ & \\
\hline FBG, $\mathrm{mmol} / \mathrm{L},(n=299)$ & $6.55(5.33-8.17)$ & $6.53(5.55-8.31)$ & 0.516 \\
\hline $\mathrm{TC}, \mathrm{mmol} / \mathrm{L},(n=297)$ & $4.08(3.37-4.93)$ & $4.35(3.51-5.12)$ & 0.123 \\
\hline $\mathrm{TG}, \mathrm{mmol} / \mathrm{L},(\mathrm{n}=297)$ & $1.01(0.74-1.47)$ & $1.20(0.85-1.68)$ & 0.028 \\
\hline $\mathrm{LDL}, \mathrm{mmol} / \mathrm{L},(\mathrm{n}=297)$ & $2.37(1.86-3.01)$ & $2.75(1.92-3.33)$ & 0.039 \\
\hline Intravenous thrombolysis, n (\%) & $143(60.1)$ & $11(16.4)$ & $<0.001$ \\
\hline Onset-to-groin puncture time, median (IQR), min & $215.5(160.0-273.3)$ & $465.0(395.0-670.0)$ & $<0.001$ \\
\hline $\mathrm{sICH}$ & $16(6.7)$ & $5(7.5)$ & 0.833 \\
\hline In-hospital mortality & $18(7.6)$ & $6(9.0)$ & 0.709 \\
\hline Successful recanalization & $202(84.9)$ & $55(82.1)$ & 0.58 \\
\hline Favorable functional outcome at 90 days, $(n=294)$ & $85(37.0)$ & $22(34.4)$ & 0.704 \\
\hline
\end{tabular}

Abbreviations: SD Standard deviation, TIA Transient ischemic attack, NIHSS National Institutes of Health Stroke Scale, IQR Interquartile range, ASPECT score Alberta Stroke Program Early CT Score, TOAST Trial of Org 10,172 in Acute Stroke Treatment, FBG Fasting blood glucose, TC Total cholesterol, TG Triglyceride, LDL Low-density lipoprotein, s/CH Symptomatic intracranial hemorrhage

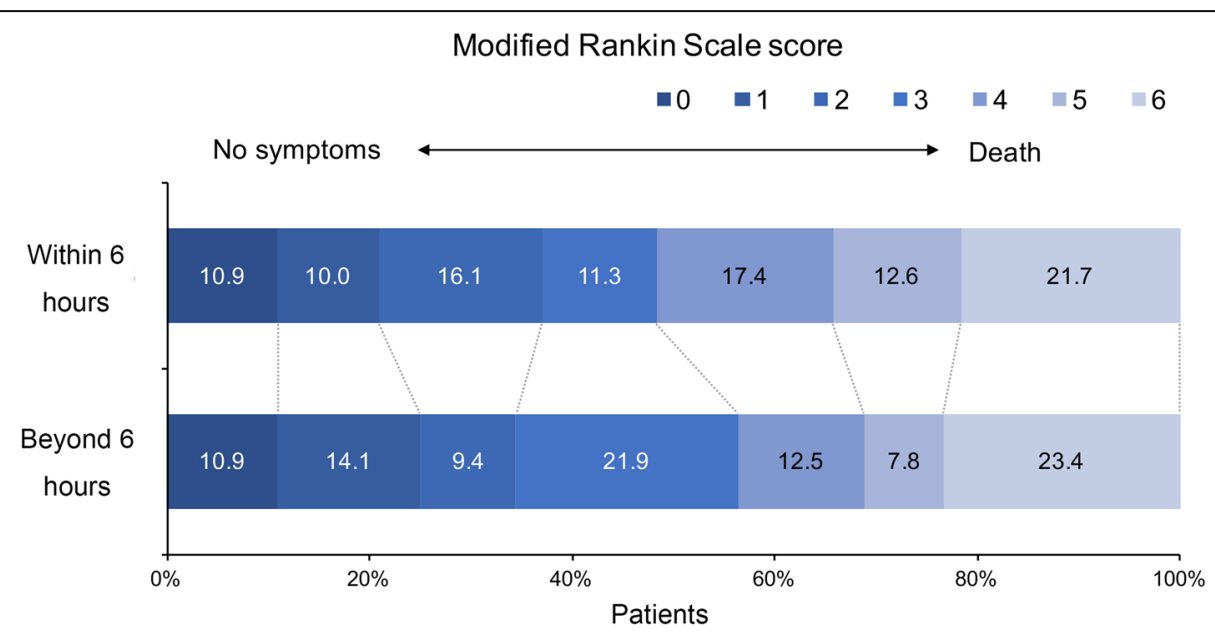

Fig. 2 Distribution of 90-day modified Rankin Scale Scores for patients treated with EVT within and beyond $6 \mathrm{~h}$ 
recanalization was achieved in 257 (84.3\%) patients and sICH occurred in $21(6.9 \%)$ patients. The in-hospital mortality was $7.9 \%$. At 90 days, 11 (3.6\%) patients were lost to follow-up and favorable functional outcome was achieved in 107 (35.1\%) patients.

Of the 305 patients included in the study, 67 (22.0\%) were treated beyond $6 \mathrm{~h}$. We compared baseline characteristics of patients treated within $6 \mathrm{~h}$ and beyond $6 \mathrm{~h}$ (Table 1). Compared with patients treated within $6 \mathrm{~h}$, patients treated beyond $6 \mathrm{~h}$ were younger $(p=0.001)$, experienced a less severe stroke $(p=0.002)$, and were less likely to receive intravenous thrombolysis $(p<0.001)$. Vascular risk profiles were also different with a lower incidence of AF $(p=0.001)$, higher TG $(p=0.028)$ and TC levels $(p=$ 0.039 ) in patients treated beyond $6 \mathrm{~h}$. There were also differences in the pathogenesis of stroke (TOAST classification) between the two groups $(p=0.006)$.

The comparison of outcomes and the distribution of $\mathrm{mRS}$ scores in patients treated within and beyond $6 \mathrm{~h}$ were reported in Table 1 and Fig. 2, respectively. No significant differences were found regarding safety $(p=$ 0.833 for sICH; $p=0.709$ for in-hospital mortality), efficacy ( $p=0.580$ for successful recanalization) and shortterm functional outcomes ( $p=0.704$ for favorable functional outcome at 90 days) between the two groups.

After adjusting for potential confounding factors, multivariable logistic regression analysis showed that the probability of successful recanalization (odds ratio [OR] $0.73,95 \%$ confidence interval $[\mathrm{CI}]: 0.31-1.73, p=0.470$, Table 2) and 90-day favorable functional outcome (OR 0.55 , 95\% CI: $0.25-1.23, p=0.145)$ in patients treated beyond $6 \mathrm{~h}$ were lower than those treated within $6 \mathrm{~h}$, but the differences were not statistically significant. There was also no significant increase in the odds of sICH (OR 2.03, 95\% CI: 0.48-8.57, $p=0.334$ ) and in-hospital mortality (OR 1.95, 95\% CI: 0.48-7.91, $p=0.348$ ) in patients treated beyond $6 \mathrm{~h}$. The result of ordinal shift analysis showed that the common OR of functional improvement was $0.80(0.45-1.42)$, indicating that EVT within $6 \mathrm{~h}$ was associated with higher odds of functional improvement, although it was not statistically significant $(p=0.450$, Table 2).

The results of interaction showed that TOAST classification did not modify the associations between onset-togroin puncture time and outcomes $(p=0.365$ for $\mathrm{sICH}$; $p=0.195$ for in-hospital mortality; $p=0.777$ for successful recanalization and $p=0.767$ for favorable functional outcome).

\section{Discussion}

In this real-world observational study, we compared the safety, efficacy, and functional outcomes between patients with anterior circulation ELVO who received EVT within $6 \mathrm{~h}$ and beyond $6 \mathrm{~h}$. The results showed that after careful assessment, EVT treatment beyond $6 \mathrm{~h}$ did not increase the risk of sICH and in-hospital mortality, nor did it offset the benefits of EVT for successful recanalization, favorable functional outcome, and functional improvement.

Recently, the results of DAWN [7] and DEFUSE-3 [8] studies showed that patients with stroke onset more than $6 \mathrm{~h}$ (6-24 h for DAWN and 6-16 h for DEFUSE-3) could still benefit from imaging-guided EVT, although the 6-h therapeutic window was recommended for EVT in the anterior circulation prior to their publication in 2018 [21]. The application of advanced imaging would give rise to EVT-eligible AIS patients presenting to a comprehensive stroke center, with $1.7 \%$ of total patients qualified for the DAWN clinical trial, and an additional 0.6 to $1 \%$ who met the DEFUSE- 3 trial registration criteria, which may increase the thrombectomy utilization and maximize patient benefits [22].

Patients treated with EVT beyond the 6-h time window in this series had a probability of favorable functional outcomes similar to those receiving EVT within 6 h. However, in the study of Jung et al., the functional outcomes were worse in the beyond $6 \mathrm{~h}$ group than the within $6 \mathrm{~h}$ group [23]. One possible explanation was that there were more patients with basilar artery occlusion in the $>6 \mathrm{~h}$ group than in the $<6 \mathrm{~h}$ group, which might

Table 2 The associations between onset-to-groin puncture time (within/beyond $6 \mathrm{~h}$ ) and outcomes

\begin{tabular}{|c|c|c|c|c|}
\hline \multirow[t]{2}{*}{ Outcomes } & \multicolumn{2}{|c|}{ Unadjusted model } & \multicolumn{2}{|c|}{ Adjusted model $^{\mathrm{a}}$} \\
\hline & OR $(95 \% \mathrm{Cl})$ & $p$ & OR $(95 \% \mathrm{Cl})$ & $p$ \\
\hline $\mathrm{sICH}$ & $1.12(0.39-3.18)$ & 0.833 & $2.03(0.48-8.57)$ & 0.334 \\
\hline In-hospital mortality & $1.20(0.46-3.16)$ & 0.709 & $1.95(0.48-7.91)$ & 0.348 \\
\hline Successful recanalization & $0.82(0.40-1.68)$ & 0.581 & $0.73(0.31-1.73)$ & 0.470 \\
\hline Favorable functional outcome at 90 days & $0.89(0.50-1.60)$ & 0.704 & $0.55(0.25-1.23)$ & 0.145 \\
\hline Functional improvement at 90 days & $1.10(0.68-1.78)$ & 0.705 & $0.80(0.45-1.42)$ & 0.450 \\
\hline
\end{tabular}

Abbreviations: OR Odds ratio, $\mathrm{Cl}$ Confidence interval, s/CH Symptomatic intracranial hemorrhage

aadjusted for age, sex, hypertension, diabetes mellitus, atrial fibrillation, smoking, baseline NIHSS, baseline ASPECT score, TOAST classification, occlusion site, FBG, TC, TG, LDL and intravenous thrombolysis 
account for the worse outcome. Likewise, Casetta et al. reported a lower probability of favorable functional outcomes in patients treated beyond $6 \mathrm{~h}$ [9]. While in contrast, an equivalent rate of favorable functional outcomes at 3 months in the early group ( 0 to $6 \mathrm{~h}$ ) was also reported when compared with that of the late group (>6h) [24], which was consistent with our findings. Similar rates of good outcomes were observed in patients receiving EVT within and beyond $8 \mathrm{~h}$ after stroke onset [25]. In another study, with revascularization as a covariate, onset-to-groin puncture time was not an independent predictor of good outcomes, but it (i.e. time window $\leq 6 \mathrm{~h}$ ) became independent when revascularization was excluded from the regression model. Their study reinforced that revascularization was a critical intermediate outcome [26]. Moreover, a recent study by Mokin et al. showed that the good clinical outcomes were identical between patients in the $0-6 \mathrm{~h}$ group, 6$16 \mathrm{~h}$ group, $16-24 \mathrm{~h}$ group and $>24 \mathrm{~h}$ group [10]. Therefore, consensus has not been reached in the comparability of favorable functional outcome for EVT beyond $6 \mathrm{~h}$ vs EVT within $6 \mathrm{~h}$, which needs to be verified by largescale clinical trials.

In our study, $7.5 \%(5 / 67)$ of the patients treated beyond $6 \mathrm{~h}$ developed $\mathrm{sICH}$, which is within the reported prevalence of sICH (3.7-11\%) in EVT beyond $6 \mathrm{~h}$ [10, $27,28]$. Besides, EVT beyond $6 \mathrm{~h}$ did not significantly increase the risk of sICH compared with EVT within $6 \mathrm{~h}$ ( $7.5 \%$ vs $6.7 \%$ ), along with previous findings demonstrating the safety of EVT beyond the 6-h time window [29, 30]. In the study of Jung et al. [23], there was no significant difference in the incidence of sICH between patients treated with intra-arterial therapy beyond $6 \mathrm{~h}$ and within $6 \mathrm{~h}$ (5.2\% vs 3.7\%). Accordingly, a recent multicenter, prospective, and observational study also showed that EVT beyond $6 \mathrm{~h}$ was safe with no increase in $\mathrm{sICH}$ [9]. Instead of EVT time, factors such as cardiogenic stroke, poor collateral circulation and higher neutrophilto-lymphocyte ratio have been reported to associate with sICH [31, 32], which could be adopted to the risk management of sICH.

In previous studies by Abilleira et al., cardioembolism seemed to be the main cause of stroke, regardless of whether the puncture time was more than $6 \mathrm{~h}$ or not (56.3\% for less than $6 \mathrm{~h}$ and $43.1 \%$ for more than $6 \mathrm{~h}$ ) [26]. In our study, $56.3 \%$ of the patients who received EVT within $6 \mathrm{~h}$ had a cardioembolic stroke. However, among the patients who received EVT beyond $6 \mathrm{~h}$, the main cause was LAA, with cardioembolism accounting for only $35.8 \%$. Earlier studies showed a contradictory relationship between the etiology of stroke and revascularization after IVT. In one study, cardioembolic stroke was considered to be easier to achieve recanalization compared with other stroke subtypes [33]. However, another study showed the opposite result: patients with extracranial carotid stenosis had higher rates of successful recanalization when treated with EVT compared to those with cardioembolic occlusions [34]. Taking into account the differences in etiology between the two groups, we further conducted an interaction analysis to investigate whether the etiology of stroke modified the associations between onset-to-groin puncture time and outcomes. The results of interaction showed that the correlation between treatment time and successful recanalization, safety and functional outcomes was not affected by the etiology of stroke.

Our study has several limitations. Firstly, this is a single-center hospital-based study, hence selection bias would be unavoidable. Secondly, some patients were lost to follow-up at 3 months. Considering that the rate of patients lost to follow-up was less than $5 \%$, the quality of this study may not be affected. Finally, we did not include medically managed stroke patients with onset beyond $6 \mathrm{~h}$ as the control group, so the clinical efficacy of EVT beyond $6 \mathrm{~h}$ was not investigated in this study.

\section{Conclusions}

In the real world, imaging-based assessment could extend the time window for EVT to beyond $6 \mathrm{~h}$ without increasing the risk of $\mathrm{sICH}$ and in-hospital mortality, nor offsetting the benefits of short-term functional improvement.

\section{Abbreviations \\ EVT: Endovascular treatment; AIS: Acute ischemic stroke; ELVO: Emergent large vessel occlusion; DEFUSE-3: Endovascular Therapy Following Imaging Evaluation for Ischemic Stroke-3; DAWN: Diffusion-Weighted Imaging or Computerized Tomography Perfusion Assessment With Clinical Mismatch in the Triage of Wake Up and Late Presenting Strokes Undergoing Neurointervention With Trevo; sICH: Symptomatic intracranial hemorrhage; LAA: Large artery atherosclerosis; NFHS: Nanjing First Hospital Stroke; CTA: CT angiography; MRA: MR angiography; mRS: Modified Rankin scale; TOAST: The Trial of Org 10,172 in Acute Stroke Treatment; NIHSS: The National Institutes of Health Stroke Scale; ASPECTS: The Alberta Stroke Programme Early CT Score; $\mathrm{mTICl}$ : The modified Thrombolysis in Cerebral Infarction; SD: Standard deviation; IQR: Interquartile range; AF: Atrial fibrillation; FBG: Fasting blood glucose; TC: Total cholesterol; TG: Triglyceride; LDL: Low-density lipoprotein; OR: Odds ratio; $\mathrm{Cl}$ : Confidence interval}

\section{Acknowledgements}

Not applicable.

\section{Authors' contributions}

$\mathrm{QH}, \mathrm{MG}, \mathrm{XC}$ and $\mathrm{YZ}$ conceptualized and designed the study. JZ, HS and XC collected the data. $\mathrm{QH}$ and $\mathrm{MG}$ analyzed the data. $\mathrm{QH}$ drafted the manuscript. QH, MG, TJ, XC and YZ revised the manuscript. The author(s) read and approved the final manuscript.

\section{Funding}

This work is supported by National Natural Science Foundation of China (81701064) and Medical Innovation Team of Jiangsu Province (CXTDA2017030).

\section{Availability of data and materials}

All the anonymized data that support the findings of this study are available from the corresponding author upon reasonable request. 


\section{Declarations}

\section{Ethics approval and consent to participate}

This study was conducted in accordance with the guidelines of the Declaration of Helsinki. The anonymized retrospective data analysis was used in the study, and therefore, ethics approval and consent to participate were waived by the ethics committee of Nanjing First hospital.

\section{Consent for publication}

Not applicable.

\section{Competing interests}

The authors declare no conflict of interest.

\section{Author details}

'Department of Neurology, Nanjing First Hospital, Nanjing Medical University, No.68, Changle Road, Nanjing, Jiangsu Province, People's Republic of China. ${ }^{2}$ School of Basic Medicine and Clinical Pharmacy, China Pharmaceutical University, Nanjing 211198, People's Republic of China.

Received: 12 January 2021 Accepted: 23 February 2021

Published online: 27 February 2021

\section{References}

1. Berkhemer OA, Fransen PS, Beumer D, van den Berg LA, Lingsma HF, Yoo $A J$, et al. A randomized trial of intraarterial treatment for acute ischemic stroke. N Engl J Med. 2015;372(1):11-20. https://doi.org/10.1056/ NEJMoa1411587.

2. Saver JL, Goyal M, Bonafe A, Diener HC, Levy El, Pereira VM, et al. Stentretriever thrombectomy after intravenous t-PA vs. t-PA alone in stroke. N Engl J Med. 2015;372(24):2285-95. https://doi.org/10.1056/NEJMoa1415061.

3. Goyal M, Demchuk AM, Menon BK, Eesa M, Rempel JL, Thornton J, et al. Randomized assessment of rapid endovascular treatment of ischemic stroke. N Engl J Med. 2015;372(11):1019-30. https://doi.org/10.1056/ NEJMoa1414905

4. Campbell BC, Mitchell PJ, Kleinig TJ, Dewey HM, Churilov L, Yassi N, et al. Endovascular therapy for ischemic stroke with perfusion-imaging selection. N Engl J Med. 2015;372(11):1009-18. https://doi.org/10.1056/NEJMoa1414 792.

5. Jovin TG, Chamorro A, Cobo E, de Miquel MA, Molina CA, Rovira A, et al. Thrombectomy within 8 hours after symptom onset in ischemic stroke. N Engl J Med. 2015;372(24):2296-306. https://doi.org/10.1056/NEJMoa1503780.

6. Saver UL, Goyal M, van der Lugt A, Menon BK, Majoie CB, Dippel DW, et al. Time to treatment with endovascular Thrombectomy and outcomes from ischemic stroke: a meta-analysis. JAMA. 2016;316(12):1279-88. https://doi. org/10.1001/jama.2016.13647.

7. Nogueira RG, Jadhav AP, Haussen DC, Bonafe A, Budzik RF, Bhuva P, et al. Thrombectomy 6 to 24 hours after stroke with a mismatch between deficit and infarct. N Engl J Med. 2018;378(1):11-21. https://doi.org/10.1056/ NEJMoa1706442.

8. Albers GW, Marks MP, Kemp S, Christensen S, Tsai JP, Ortega-Gutierrez S, et al. Thrombectomy for stroke at 6 to 16 hours with selection by perfusion imaging. N Engl J Med. 2018;378(8):708-18. https://doi.org/10.1056/ NEJMoa1713973.

9. Casetta I, Fainardi E, Saia V, Pracucci G, Padroni M, Renieri L, et al. Endovascular Thrombectomy for acute ischemic stroke beyond 6 hours from onset: a real-world experience. Stroke. 2020;51(7):2051-7. https://doi. org/10.1161/STROKEAHA.119.027974.

10. Mokin M, Abou-Chebl A, Castonguay AC, Nogueira RG, English JD, Farid H, et al. Real-world stent retriever thrombectomy for acute ischemic stroke beyond 6 hours of onset: analysis of the NASA and TRACK registries. J Neurointerv Surg. 2019;11(4):334-7. https://doi.org/10.1136/neurintsurg-201 8-014272

11. Gorelick PB, Wong KS, Bae HJ, Pandey DK. Large artery intracranial occlusive disease: a large worldwide burden but a relatively neglected frontier. Stroke. 2008;39(8):2396-9. https://doi.org/10.1161/STROKEAHA.107.505776.

12. Wang $Y$, Zhao $X$, Liu L, Soo YO, Pu Y, Pan Y, et al. Prevalence and outcomes of symptomatic intracranial large artery stenoses and occlusions in China: the Chinese intracranial atherosclerosis (CICAS) study. Stroke. 2014:45(3): 663-9. https://doi.org/10.1161/STROKEAHA.113.003508.
13. Liu X, Xu G, Wu W, Zhang R, Yin Q, Zhu W. Subtypes and one-year survival of first-ever stroke in Chinese patients: the Nanjing stroke registry. Cerebrovasc Dis. 2006;22(2-3):130-6. https://doi.org/10.1159/000093241.

14. Chen X, Huang Q, Deng Q, Shen R, Liu Y, Lu M, et al. A prediction model of brain edema after endovascular treatment in patients with acute ischemic stroke. J Neurol Sci. 2019;407:116507. https://doi.org/10.1016/j.jns.2019.11 6507.

15. Flottmann F, Broocks G, Faizy TD, McDonough R, Watermann L, DebChatterji $\mathrm{M}$, et al. Factors associated with failure of reperfusion in endovascular therapy for acute ischemic stroke : a multicenter analysis. Clin Neuroradiol. 2020. https://doi.org/10.1007/s00062-020-00880-8.

16. Barber PA, Demchuk AM, Zhang J, Buchan AM. Validity and reliability of a quantitative computed tomography score in predicting outcome of hyperacute stroke before thrombolytic therapy. ASPECTS Study Group. Alberta Stroke Programme Early CT Score. Lancet. 2000;355(9216):1670-4. https://doi.org/10.1016/s0140-6736(00)02237-6.

17. Broocks G, Kniep H, Schramm P, Hanning U, Flottmann F, Faizy T, et al. Patients with low Alberta stroke program early CT score (ASPECTS) but good collaterals benefit from endovascular recanalization. J Neurointerv Surg. 2020;12(8):747-52. https://doi.org/10.1136/neurintsurg-2019-015308.

18. von Kummer R, Broderick JP, Campbell BC, Demchuk A, Goyal M, Hill MD, et al. The Heidelberg bleeding classification: classification of bleeding events after ischemic stroke and reperfusion therapy. Stroke. 2015;46(10):2981-6. https://doi.org/10.1161/STROKEAHA.115.010049.

19. Zaidat OO, Yoo AJ, Khatri P, Tomsick TA, von Kummer R, Saver JL, et al. Recommendations on angiographic revascularization grading standards for acute ischemic stroke: a consensus statement. Stroke. 2013;44(9):2650-63. https://doi.org/10.1161/STROKEAHA.113.001972.

20. Xiao L, Ma M, Gu M, Han Y, Wang H, Zi W, et al. Renal impairment on clinical outcomes following endovascular recanalization. Neurology. 2020; 94(5):e464-e73. https://doi.org/10.1212/WNL.0000000000008748.

21. Polish Thrombectomy I, Slowik A, Wnuk M, Brzegowy P, ChrzanowskaWasko J, Golenia A, et al. Mechanical thrombectomy in acute stroke - five years of experience in Poland. Neurol Neurochir Pol. 2017;51(5):339-46. https://doi.org/10.1016/j.pjnns.2017.05.004.

22. Jadhav AP, Desai SM, Kenmuir CL, Rocha M, Starr MT, Molyneaux BJ, et al. Eligibility for endovascular trial enrollment in the 6- to 24-hour time window: analysis of a single comprehensive stroke center. Stroke. 2018; 49(4):1015-7. https://doi.org/10.1161/STROKEAHA.117.020273.

23. Jung S, Gralla J, Fischer U, Mono ML, Weck A, Ludi R, et al. Safety of endovascular treatment beyond the 6-h time window in 205 patients. Eur J Neurol. 2013;20(6):865-71. https://doi.org/10.1111/ene.12069.

24. Abou-Chebl A. Endovascular treatment of acute ischemic stroke may be safely performed with no time window limit in appropriately selected patients. Stroke. 2010:41(9):1996-2000. https://doi.org/10.1161/STROKEA HA.110.578997.

25. Gratz PP, Jung S, Schroth G, Gralla J, Mordasini P. Hsieh K, et al. Outcome of standard and high-risk patients with acute anterior circulation stroke after stent retriever thrombectomy. Stroke. 2014:45(1):152-8. https://doi.org/10.11 61/STROKEAHA.113.002591.

26. Abilleira S, Cardona P, Ribo M, Millan M, Obach V, Roquer J, et al. Outcomes of a contemporary cohort of 536 consecutive patients with acute ischemic stroke treated with endovascular therapy. Stroke. 2014;45(4):1046-52. https://doi.org/10.1161/STROKEAHA.113.003489.

27. Menon BK, d'Esterre CD, Qazi EM, Almekhlafi M, Hahn L, Demchuk AM, et al. Multiphase $C T$ angiography: a new tool for the imaging triage of patients with acute ischemic stroke. Radiology. 2015;275(2):510-20. https://doi.org/1 0.1148 /radiol.15142256.

28. Beckhauser MT, Castro-Afonso LH, Dias FA, Nakiri GS, Monsignore LM, Martins Filho RK, et al. Extended Time Window Mechanical Thrombectomy for Acute Stroke in Brazil. J Stroke Cerebrovasc Dis. 2020;29(10):105134. https://doi.org/10.1016/j.jstrokecerebrovasdis.2020.105134.

29. Alsahli K, Cheung AK, Wijesuriya N, Cordato D, Zagami AS, Wenderoth JD, et al. Thrombectomy in stroke of unknown onset, wake up stroke and late presentations: Australian experience from 2 comprehensive stroke centres. J Clin Neurosci. 2019:59:136-40. https://doi.org/10.1016/j.jocn.2018.10.114.

30. Goyal N, Tsivgoulis G, Frei D, Turk A, Baxter B, Froehler MT, et al. A multicenter study of the safety and effectiveness of mechanical thrombectomy for patients with acute ischemic stroke not meeting top-tier evidence criteria. J Neurointerv Surg. 2018;10(1):10-6. https://doi.org/10.113 6/neurintsurg-2016-012905. 
31. Switonska M, Piekus-Slomka N, Slomka A, Sokal P, Zekanowska E, Lattanzi S. Neutrophil-to-lymphocyte ratio and symptomatic hemorrhagic transformation in ischemic stroke patients undergoing revascularization. Brain Sci. 2020;10:11. https://doi.org/10.3390/brainsci10110771.

32. Hao Y, Yang D, Wang H, Zi W, Zhang M, Geng Y, et al. Predictors for symptomatic intracranial hemorrhage after endovascular treatment of acute ischemic stroke. Stroke. 2017;48(5):1203-9. https://doi.org/10.1161/STROKEA HA.116.016368.

33. Molina CA, Montaner J, Arenillas JF, Ribo M, Rubiera M, Alvarez-Sabin J. Differential pattern of tissue plasminogen activator-induced proximal middle cerebral artery recanalization among stroke subtypes. Stroke. 2004; 35(2):486-90. https://doi.org/10.1161/01.STR.0000110219.67054.BF.

34. Hussain MS, Lin R, Cheng-Ching E, Jovin TG, Moskowitz Sl, Bain M, et al. Endovascular treatment of carotid embolic occlusions has a higher recanalization rate compared with cardioembolic occlusions. J Neurointer Surg. 2010;2(1):71-3. https://doi.org/10.1136/jnis.2009.001081.

\section{Publisher's Note}

Springer Nature remains neutral with regard to jurisdictional claims in published maps and institutional affiliations.

Ready to submit your research? Choose BMC and benefit from:

- fast, convenient online submission

- thorough peer review by experienced researchers in your field

- rapid publication on acceptance

- support for research data, including large and complex data types

- gold Open Access which fosters wider collaboration and increased citations

- maximum visibility for your research: over $100 \mathrm{M}$ website views per year

At BMC, research is always in progress.

Learn more biomedcentral.com/submissions 